\title{
Laboratory Test Results Supplemental Qualifiers Dataset
}

National Cancer Institute

\section{Source}

National Cancer Institute. Laboratory Test Results Supplemental Qualifiers Dataset. NCI

Thesaurus. Code C147220.

A dataset containing supplemental information, specifically non-standard variables, to parent records in the laboratory test results domain. 